\title{
1 Managing uncertainty in soil carbon feedbacks to climate change
}

3 Mark A. Bradford ${ }^{1,2}$, William R. Wieder ${ }^{3,4}$, Gordon B. Bonan ${ }^{3}$, Noah Fierer ${ }^{5,6}$, Peter A.

4 Raymond $^{1}$ \& Thomas W. Crowther ${ }^{1,2}$

5

$6 \quad{ }^{1}$ School of Forestry and Environmental Studies, Yale University, New Haven, CT 06511, USA

$7 \quad{ }^{2}$ Department of Terrestrial Ecology, Netherlands Institute of Ecology (NIOO-KNAW), 6700 AB

8 Wageningen, The Netherlands

$9{ }^{3}$ Climate and Global Dynamics Laboratory, National Center for Atmospheric Research, Boulder, CO

10 80307, USA

$11{ }^{4}$ Institute for Arctic and Alpine Research, University of Colorado, Boulder, CO, 80309, USA

$12{ }^{5}$ Department of Ecology and Evolutionary Biology, University of Colorado, Boulder, CO, 80309, USA

$13{ }^{6}$ Cooperative Institute for Research in Environmental Sciences, University of Colorado, Boulder, CO

14 80309, USA

15

16 Email addresses: mark.bradford@yale.edu; wwieder@ucar.edu; bonan@ucar.edu;

17 noah.fierer@colorado.edu; peter.raymond@yale.edu; t.crowther@nioo.knaw.nl

19 Planetary warming may be exacerbated if it accelerates loss of soil carbon to the

20 atmosphere. This carbon cycle-climate feedback is included in climate projections. Yet

21 despite ancillary data supporting a positive feedback, there is limited evidence for soil

22 carbon loss under warming. The low confidence engendered in feedback projections is

23 reduced further by the common representation in models of an outdated knowledge of soil

24 carbon turnover. 'Model-knowledge integration' - representing in models an advanced 
understanding of soil carbon stabilisation - is the first step to build confidence. This will inform experiments that further increase confidence by resolving competing mechanisms

27 that most influence projected soil carbon stocks. Improving feedback projections is an

28 imperative for establishing greenhouse gas emission targets that limit climate change.

30 Hundreds of studies have shown effects of warming on soil carbon (C) dynamics ${ }^{1,2}$. Much of this

31 empirical research has been motivated by the possibility that climate warming will stimulate

32 biologically mediated decomposition of soil $\mathrm{C}$ to $\mathrm{CO}_{2}{ }^{3-7}$. Enhanced rates of soil $\mathrm{C}$ decomposition

33 may reduce the capacity of the land to act as a $\mathrm{CO}_{2}$ sink, so that a greater proportion of

34 anthropogenic $\mathrm{CO}_{2}$ emissions remain in the atmosphere ${ }^{8-10}$. The magnitude of this so-called

35 'carbon-climate feedback' is therefore critical for estimating the allowable greenhouse gas

36 emissions that are compatible with climate $\operatorname{targets}^{10}$. The soil is the largest store of C $(\sim 1,500$ -

$372,400 \mathrm{Pg}$ ) in the terrestrial biosphere, containing more than double the $\mathrm{C}$ of the atmosphere ${ }^{11-13}$.

38 Hence, loss of even a small proportion of this store may result in higher atmospheric $\mathrm{CO}_{2}$

39 concentrations and consequently additional planetary warming ${ }^{8,14}$.

40 Despite the wealth of research into warming effects on soil $\mathrm{C}$ dynamics, there is no

41 consensus on the magnitude of warming-induced reductions in soil C stocks ${ }^{1,14,15}$. The low

42 confidence in the projected range of soil $\mathrm{C}$ losses arises in part from an empirical focus on the

43 responses of soil $\mathrm{C}$ decomposition rates to warming, rather than the direct measurement of

44 changes in total soil C stocks. Confidence in projected losses is further eroded because emerging

45 ideas $^{2,16}$ about how soil $\mathrm{C}$ is formed and stabilised are not commonly represented in the soil

46 biogeochemical models used for climate change projections ${ }^{17-19}$. Instead, the assumptions in

47 these models about the mechanisms underlying soil $\mathrm{C}$ responses to warming are largely 
48 similar ${ }^{11,14,20,21}$ and often conflict with emerging understanding ${ }^{16,22,23}$. These assumptions

49 underlie Earth System Model (ESM) projections of soil C losses through climate warming ${ }^{9,24}$.

50 The ESMs are the most complex of the climate models, and incorporate the global C

51 cycle to simulate how the atmosphere and biosphere interact to shape climate trajectories ${ }^{11}$. The

52 ESM projections of warming-induced soil C losses range from minimal, to a third of the stock

53 lost by $2100^{8,9,25}$. The ESM characteristics generating this wide range in the projected magnitude

54 of the feedback are well documented, involving uncertainties in the parameter values used to

55 control the rate at which soil $\mathrm{C}$ decomposes and the sensitivity of this rate to warming ${ }^{26,27}$.

56 Reducing these parameter uncertainties will do little to build confidence in the magnitude of the

57 modelled feedback.

58 In this paper, we distinguish the meaning of 'uncertainty' from 'confidence'. Many forms

59 of uncertainty exist when modelling climate change and associated biosphere feedbacks ${ }^{28}$, but

60 they do not equally contribute to the confidence one has that projected changes will occur ${ }^{29}$. We

61 focus on the major uncertainties underpinning low confidence in projections of soil C stock

62 responses to warming. Three primary areas of empirical uncertainty exist: the paucity of direct

63 observations of warming effects on soil C stocks, the potential for organism responses to

64 warming to alter short-term biogeochemical responses, and dramatically changing ideas about

65 how soil $\mathrm{C}$ formation and stabilisation are regulated. The major modelling uncertainty is

66 associated with representing common and out-dated ideas about soil C turnover in the soil sub-

67 models of the ESMs. We demonstrate the importance of instead representing different ideas in

68 ESMs - i.e. 'structural uncertainties' - that capture emerging concepts of soil C stabilisation. We

69 conclude by proposing ways forward for empiricists and modellers to improve confidence in

70 projected soil C-climate feedbacks. 


\section{Empirical uncertainties}

\section{Evidence for carbon loss}

74 Empirical research into soil $\mathrm{C}$ stock responses to warming has primarily focused on

75 decomposition (Fig. 1). There is compelling evidence from observational studies across climate

76 gradients, and both laboratory and field warming experiments, that decomposition rates respond

77 positively to warming (but see ${ }^{15}$ ), at least in the short-term $(<1 \text { to } \sim 10 \text { years })^{1,2,30}$. These

78 increases in decomposition of soil $\mathrm{C}$ to $\mathrm{CO}_{2}$ occur with plants present or absent, suggesting that

79 warming accelerates $\mathrm{C}$ loss from soils primarily by stimulating the activities of microbes ${ }^{31}$. This

80 microbial mechanism underlies the C-cycle pathway in the ESMs through which soil $\mathrm{C}$ is

81 redistributed to the atmosphere as climate warms.

82 The soil $\mathrm{C}$ stock is not, however, just determined by microbial decomposition rates.

83 Changes in the soil $\mathrm{C}$ stock are the net product of outputs (decomposition) and also inputs (soil C

84 formation, Fig. 1). More rapid decomposition is then not synonymous with reductions in total

85 soil $\mathrm{C}$ stocks $^{15}$ if coupled with similar increases in soil $\mathrm{C}$ formation. The idea that soil $\mathrm{C}$ stocks

86 are the net outcome of inputs and outputs seems obvious and is captured by the soil sub-models

87 in the $\mathrm{ESMs}^{27}$. Yet expectations for reductions in soil $\mathrm{C}$ under warming are still primarily driven

88 by empirical data of accelerated decomposition rates ${ }^{1}$, despite little evidence that decomposition

89 responses can be used to infer responses in soil $\mathrm{C}$ stocks ${ }^{1,32}$. In a synthesis of field data, for

90 example, the mean effect size of warming on decomposition rates was statistically significant

91 and strongly positive ${ }^{2}$. However, the same meta-analysis showed that the mean effect of

92 warming on soil $\mathrm{C}$ stocks was indistinguishable from zero. Collectively then the plethora of 
93 studies reporting positive decomposition responses to warming provide weak, indirect support

94 for the existence of a positive land C-climate feedback ${ }^{1,5,6}$.

95 The lack of direct evidence for reductions in soil C stocks may, in part, reflect a signal-to-

96 noise issue. Soil C varies markedly at nanometre to metre scales in amount, chemistry, and the

97 physical setting where it is found $\mathrm{d}^{33,34}$. These attributes can protect soil $\mathrm{C}$ from microbial

98 decomposition, meaning that a large proportion of the $\mathrm{C}$ in a given soil will respond slowly, if at

99 all, to warming ${ }^{1}$. Looking for a small change in a large, spatially variable stock makes it difficult

100 to quantify effects of warming on total soil C (Fig. 1). For example, the statistical power to detect

101 a change in total soil C stocks at a site is typically far below that recommended, demanding

102 higher replication than generally used ${ }^{35}$. The use of techniques, such as isotopes and

103 fractionations, to track and quantify $\mathrm{C}$ turnover in soil pools that are differently vulnerable, does

104 offer a solution for detecting a signal from among the noise ${ }^{36-39}$. However, the issues with using

105 such techniques to infer change in stock sizes echoes those for decomposition; environmental

106 change can alter the sizes of individual C pools or fluxes without altering the total stock ${ }^{40}$.

107 The difficulties involved in detecting changes in the total size of soil C stocks likely

108 encouraged the use of indirect measurements, such as decomposition rates, to understand

109 warming effects. However, demonstrating definitively that soil C stocks will be reduced under

110 warming requires a large number of sites, long time scales ( $>20$ years), and ecosystem (versus

111 soil only) experimental warming. Such long-term network data will not be available in the near

112 term ${ }^{41}$ but even collation of soil C stocks in existing field studies would be a step forward. We

113 know of only five, published field-warming studies that measured soil C directly under

114 experimental warming plots for timescales $>10$ years, and they did not consistently show

115 reductions in soil $\mathrm{C}^{2,42}$. Furthermore, of the 34 studies that have compared soil $\mathrm{C}$ dynamics in 
116 control versus experimental warming plots ${ }^{2,42}-$ over both the short and longer-term - only six

117 measured stocks. The remainder measured soil $\mathrm{C}$ concentrations but these do not account for

118 potential changes in soil bulk density, which could markedly affect stock sizes ${ }^{43,44}$. A key

119 challenge then is determining how best to improve confidence in projected soil C-climate

120 feedbacks in lieu of the fact that there is limited direct data on the effects of ecosystem warming

121 on total soil C stocks.

122

123 Organisms modify direct warming effects

124 Knowing how to best represent organismal responses to climate change in biogeochemical

125 models is a significant challenge ${ }^{45}$. Initial effects of chronic disturbance on an ecosystem are

126 often transient because the organisms, whose activities mediate biogeochemical processes such

127 as decomposition, first respond physiologically and second through changes in abundance (Fig.

$1282)^{46}$. Two decades of experimental summer warming of arctic tundra, for example, gradually

129 increased the dominance of woody plants, altering plant community architecture. The altered

130 plant community mitigated direct summer warming of the soils but caused indirect warming in

131 the winter. These longer-term consequences stimulated plant $\mathrm{C}$ inputs at depth, increasing both

132 the activity of the soil microbes and soil $\mathrm{C}$ storage, despite the fact that initial warming was

133 considered to promote soil C $10 s^{42}$.

134 Soil microbial communities and controls on their activities also shift as temperatures

135 change, altering their collective responses to warming in the shorter- versus longer-term ${ }^{4,5,47-50}$.

136 Substantive debate exists as to whether these shifts will influence soil $\mathrm{C}$ decomposition

137 rates $^{5,46,47,51}$. Adding to this uncertainty, new efforts to incorporate soil microbial processes in 
138 biogeochemical models reveal that the manner in which they are represented means that

139 simulated acclimation to warming can alternatively exacerbate or mitigate soil C losses ${ }^{4,52,53}$.

140 Some organismal responses to warming are incorporated in ESM formulations. For

141 example, positive responses of plant production to warming are expected in cold, high-latitude

142 systems because higher temperatures extend the growing season ${ }^{42}$. Most ESMs then project an

143 increase in land-C stocks at high latitudes because increased plant-C inputs to soils more than

144 offset increases in soil $\mathrm{C}$ decomposition rates ${ }^{11,54}$. Both model and empirical findings therefore

145 highlight that warming responses of organisms influencing either soil $\mathrm{C}$ inputs or outputs will

146 likely alter direct effects of warming on soil C stocks. The reality, however, is that we do not

147 know whether the collective effects of these organismal responses under warming will amplify,

148 dampen or little influence direct warming-induced changes in the global stock of soil C.

\section{Changing ideas on soil carbon stabilisation}

151 Low temperature is considered to be one of the dominant forces protecting soil $\mathrm{C}$ from

152 decomposition ${ }^{55}$. In permafrost soils (those that are $\leq 0^{\circ} \mathrm{C}$ for $>2$ years) decomposition proceeds

153 slowly because of limited availability of liquid water ${ }^{56,57}$. As liquid water becomes available,

154 microbial decomposition of soil C initially proceeds slowly because cool temperatures directly

155 limit activity ${ }^{58}$. Warming then releases temperature limitation on the catalytic activities of

156 intracellular and extracellular microbial enzymes, accelerating decomposition of soil $\mathrm{C}$ to $\mathrm{CO}_{2}$.

157 The land C-climate feedback in ESMs is primarily based on the assumption of this fundamental

158 biochemical response ${ }^{59}$. But a paradigmatic shift in our understanding of how soil C is

159 stabilised ${ }^{60}$ casts doubt on whether such cellular processes can be directly scaled to biosphere-

160 atmosphere interactions driving the $\mathrm{C}$ cycle. 
162 over a century. They are now also recognised, somewhat paradoxically, as dominant agents of 163 soil C formation (Fig. 3) ${ }^{16,23,61}$. As much as $80 \%$ of the soil C in mineral soils that is protected

164 from decomposition through physico-chemical mechanisms, exists in the form of microbial 165 necromass and products ${ }^{62}$, and the proportion may be higher at depth ${ }^{63}$. Soil microbes therefore 166 convert large fractions of plant-C inputs to $\mathrm{CO}_{2}$ and a smaller fraction into stable soil $\mathrm{C}^{36}$. The 167 process has been likened to a microbial funnel, whereby microorganisms consume unprotected C 168 and a portion that passes through is converted into decomposition-resistant forms ${ }^{36,50,64}$. This 169 dual role for microbes raises the possibility that warming could accelerate the decomposition and 170 stabilisation of soil $\mathrm{C}$, shifting stocks toward proportionally more protected forms of $\mathrm{C}$ which are 171 less sensitive to warming (Fig. 3$)^{65}$.

172 The emerging paradigm of soil $\mathrm{C}$ formation emphasises microbial growth efficiencies

173 and mineral-matrix interactions as dominant forces stabilising soil $C^{16,23,66,67}$. Structural plant 174 compounds such as lignin, previously considered resistant to microbial decomposition ${ }^{66,68}$, 175 represent a poor quality substrate for microbial growth. Physiological inefficiencies involved in 176 growing on poor substrates result in more plant $\mathrm{C}$ being respired to $\mathrm{CO}_{2}$ instead of being 177 transformed to microbial biomass ${ }^{4}$. Under this paradigm, most stable $\mathrm{C}$ in mineral soils is 178 produced via microbial uptake of primarily metabolic plant matter inputs, which microbes 179 rapidly decompose and convert to biomass efficiently (Fig. 3) ${ }^{23,69}$. The dominant pathway for 180 these inputs may be via plant roots and their associated mycorrhizal fungi ${ }^{70,71}$. If this paradigm is 181 applicable across multiple ecosystems, it could help explain why increased inputs of structural 182 plant $\mathrm{C}$ to soils, from aboveground litter sources, may not translate to higher soil $\mathrm{C}$ stocks ${ }^{40,72}$. 
184 clays, are required to protect them from decomposition ${ }^{22,34}$. Hence, even in wet tropical

185 rainforests, large stores of soil $\mathrm{C}$ can be found in aerobic, mineral soils where decomposition

186 should otherwise be rapid ${ }^{12}$. The most vulnerable pools of soil $\mathrm{C}$ to warming are likely those in

187 organic-rich soils, such as wetlands and in permafrost, where the lack of oxygen and liquid

188 water, respectively, slow microbial decomposition. In such systems much of the soil C has not

189 passed through the microbial funnel, but exists as relatively undecomposed plant material ${ }^{16}$. With

190 warming, $\mathrm{C}$ in these soils will increasingly pass through the funnel, resulting in a major fraction

191 being decomposed to $\mathrm{CO}_{2}$ and a small fraction becoming microbial products available for "re-

192 stabilisation". Yet wetland and permafrost soils are poorly represented in ESM simulations of

193 land C-climate feedbacks (but see ${ }^{73}$ ) and there is little data available to estimate the likely

194 magnitude of their response to climate change ${ }^{11,58,74}$. Given that permafrost contains as much C

195 as all non-permafrost soils combined ${ }^{13}$, such limitations must be addressed given the potential

196 importance of their responses in dictating the magnitude of land C-climate feedbacks ${ }^{73}$.

\section{Uncertainties in modelling}

\section{Model structure}

200 The soil sub-models in ESMs represent soil C responses to warming in a common manner. Soil

$201 \mathrm{C}$ decomposition to $\mathrm{CO}_{2}$ follows a single first-order response curve, similar to half-life plots for

202 radioactive decay, where the time taken for a constant fraction of soil C to decompose decreases

203 with warming ${ }^{21,27,75,76}$. The mechanism then assumes that climate warming increases the short

204 and long-term potential for microbes to decompose soil $\mathrm{C}$ to $\mathrm{CO}_{2}{ }^{8-10}$, presupposing a positive $\mathrm{C}$ -

205 climate feedback ${ }^{14}$. 
This representation of soil C turnover in ESMs has remained essentially unchanged for

207 two decades ${ }^{20,21}$. Over the same time, advances in climate change projection have been made by

208 representing different mechanisms thought to underlie responses of the physical climate system

209 to anthropogenic emissions ${ }^{29,77,78}$. For the physical climate, the spread in an ensemble of model

210 projections with the same scenario forcing is taken as a measure of model uncertainty ${ }^{28,29,74,78}$. A

211 similar principle has been applied to C cycle projections in ESMs $s^{9,11,14,24}$ but the validity of doing

212 so is questionable. Specifically, the use of multi-model ensembles underlies the Coupled Model

213 Intercomparison Project (CMIP), which is a hallmark of the Intergovernmental Panel on Climate

214 Change (IPCC) assessment reports ${ }^{78}$. A key objective of the CMIP is to quantify the influence of

215 structural uncertainty, reflected in representing different mechanisms among models, on

216 projected climate change $\mathrm{e}^{28,29,77}$. Yet, because they represent common mechanisms for soil C

217 turnover, the broad spread among ESMs in the magnitude of projected land C-climate

218 feedbacks ${ }^{8-10,74}$ is not the consequence of structural uncertainty ${ }^{26,54}$.

219 Differences among soil sub-model projections instead result largely from parameter

220 uncertainty. Values for parameters such as the "decay constant" for soil C, contribute to a six-

221 fold difference in the simulated global stock of contemporary soil $\mathrm{C}^{27}$. Differences in the

222 simulated stocks carry forward and translate to substantial among-model variation in the strength

223 of C-climate feedback projections ${ }^{26,54,79}$. Efforts to refine parameter estimates may reduce

224 among-model variation ${ }^{80}$ but will not improve confidence in projected soil $\mathrm{C}$ stock responses to

225 warming ${ }^{26,81}$. These improvements will only come through representing the new ideas about the

226 mechanisms regulating soil $\mathrm{C}$ turnover.

227 Representing structural uncertainty in soil processes in the ESMs has the potential to

228 drastically change projected terrestrial C cycle feedbacks. For example, beyond warming the 
$229 \mathrm{CO}_{2}$ fertilization effect is a dominant biogeochemical feedback in ESMs ${ }^{9}$. Increasingly, model

230 structures represent the fact that the rate of soil nitrogen (N) supply can strongly constrain plant

231 growth responses to elevated atmospheric $\mathrm{CO}_{2}{ }^{82}$. In general, representing coupled C-N

232 biogeochemistry dampens the $\mathrm{CO}_{2}$ fertilization effect on plant productivity and reduces

233 terrestrial $\mathrm{C}$ storage ${ }^{83,84}$. Given the complexity of representing global $\mathrm{C}$ and $\mathrm{N}$ cycles, inclusion

234 of terrestrial $\mathrm{N}$ dynamics may increase $\mathrm{C}$ cycle uncertainty, but should build confidence in model

235 projections. Similarly, recent efforts to represent structural uncertainty in soil C responses to

236 warming in soil biogeochemical models ${ }^{19,85-87}$ suggest that divergent projections of the C-climate

237 feedback will be observed if these efforts are integrated into CMIP exercises. We argue that such

238 initiatives are necessary to represent the true uncertainty associated with projecting terrestrial

239 biogeochemical responses to climate change.

\section{Advances in soil biogeochemical models}

242 Many of the ESMs simulate soil processes by using some of the most widely applied, soil

243 biogeochemical models ${ }^{27}$. These 'conventional' soil models assume that decomposition of soil C

244 to $\mathrm{CO}_{2}$ is a product of microbial activity, but that microbes do not regulate the rate of soil $\mathrm{C}$

245 turnover ${ }^{88}$. Instead, the control on turnover is exerted by factors such as the chemistry of

246 different soil C compounds ${ }^{60}$. These conventional models therefore explicitly represent controls

247 on microbial activity, but the microbes themselves are considered 'implicit' to the dynamics.

248 Recent major advances in understanding soil $\mathrm{C}$ dynamics have come about in the broader context

249 of soil biogeochemical models (as opposed to the narrow subset of these models used in the

250 ESMs) by representing explicitly how microbial physiology, biomass and enzyme kinetics

251 respond to warming ${ }^{27,48,65}$. 
253 warming were observed with a conventional model structure but not with a microbial-explicit

254 structure, despite the assumption that all of the processes were temperature sensitive $\mathrm{e}^{52}$. The

255 difference in model structure was that, in the latter case, the microbial biomass controlled soil C

256 decomposition rates via production of degradative enzymes. As microbial biomass and hence

257 enzyme production declined over time, because warming was assumed to reduce microbial

258 growth efficiencies ${ }^{59}$, decomposition slowed and soil C stocks were maintained. Whereas the

259 conventional model projected that warming would reduce soil C stocks, because the first-order

260 decay mechanism assumes soil $\mathrm{C}$ decomposition rates are independent of the size of the

261 microbial biomass ${ }^{52}$. Whether the microbial-explicit models are a more accurate mechanistic

262 representation of soil $\mathrm{C}$ dynamics is unknown. However, they have been shown to improve the

263 ability of conventional soil $\mathrm{C}$ model structures to estimate observed spatial variation and stock

264 sizes of global soil C, as well as their responses to environmental change ${ }^{19,85-87}$.

265 Another 'implicit' assumption of most conventional soil models is that the rate of soil C

266 formation (as opposed to decomposition) is regulated by microbial growth efficiencies, with

267 higher efficiencies leading to higher formation rates ${ }^{89}$. Warming-induced reductions in growth

268 efficiencies then exacerbate, rather than mitigate as estimated by microbial-explicit models,

269 losses of soil $\mathrm{C}$ stocks ${ }^{4}$. Although microbial growth efficiencies are assumed to be invariant in

270 most conventional models (an assumption that is under debate ${ }^{4,90}$ ), the example demonstrates

271 that even slight structural differences in how soil $\mathrm{C}$ turnover is represented can translate to a

272 broad spread in the projected magnitude of soil C losses. Until such structural uncertainties are

273 represented in ESM soil sub-models, we cannot know whether the spread in the projected

274 magnitude of the C-climate feedback is reflective of our contemporary conceptual understanding 
275 of soil C turnover. As such there is low confidence in the current ESM projections of the C-

276 climate feedback and the resulting constraints on allowable greenhouse gas emissions ${ }^{14,74}$.

\section{Addressing uncertainties to build confidence}

279 We have neither those data nor the models required to reliably determine how soil C stocks will

280 be affected by a warmer world. These realities suggest a need for modellers and empiricists to

281 collaborate to increase confidence in the magnitude of projected C-climate feedbacks. Such

282 collaborations will succeed through an open discussion - of the knowledge and data gaps in soil

283 C research - between the more geophysical-based Earth system modelling community and the

284 more ecological-based empirical community ${ }^{91}$.

285 We propose four ways forward for modellers and empiricists to focus efforts on

286 identifying and addressing critical and tangible assumptions that generate low confidence in

287 projected soil C stock responses. The overarching idea is to induce an exchange cycle of model

288 and empirical insights that rapidly advance mechanistic understanding of how soil C is formed,

289 stabilised, and decomposed. The expectation is that these advances in mechanistic understanding

290 will improve confidence in soil C stock responses to warming, at timescales more attractive than

291 those required to assemble direct field observations of soil C stock responses to long-term,

292 chronic ecosystem warming. Importantly, the development of physical climate models shows

293 that higher confidence in feedback projections may be achieved through better representation of

294 mechanisms, even when this does not reduce the spread among model projections ${ }^{29}$. We suggest

295 that the aims for soil biogeochemistry should mirror these developments, with the primary focus

296 on representing and improving our basic understanding of soil C cycling and a secondary focus

297 on reducing the spread among models in the magnitude of projected feedbacks (Fig. 4). 


\section{Represent structural uncertainty}

300 The most important near-term goal in Earth System modelling efforts focused on the land C-

301 climate feedback, should be to represent theoretical uncertainty in soil C decomposition and

302 formation processes through different underlying model structures. The major advances in

303 representing such structural uncertainty in microbial-explicit soil biogeochemical

304 models $^{48,52,63,65,92}$ should facilitate rapid adoption of competing assumptions in soil sub-models

305 embedded within ESMs. The fundamental approach should emulate standard practices in the

306 atmospheric sciences to sample model structural uncertainty through multi-model ensembles ${ }^{28}$.

307 The standardised protocols, however, should more narrowly compare different mechanistic

308 representations of soil $\mathrm{C}$ decomposition and formation within a common modelling framework

309 (e.g. different soil biogeochemical models within the same ESM). If these intracomparison

310 efforts are computationally too expensive at the level of complexity of ESMs, it is feasible to

311 compare structurally distinct soil biogeochemical models within the land models that are a

312 component of ESMs ${ }^{19,93}$. Adopting these systematic intracomparisons will facilitate effective

313 model evaluation and improvement at regional to global scales.

314 Empiricists have two distinct roles to play in these model intracomparison projects. The

315 first is to work with modellers to develop structural representations that best reflect the

316 competing conceptualisations of soil $\mathrm{C}$ turnover. We refer to this approach as 'model-knowledge

317 integration' to distinguish it from the now ubiquitous model-data synthesis efforts, which have

318 failed to redress the low confidence in soil C-climate feedbacks. Model-knowledge integration

319 will likely involve synthesising hundreds of published mathematical and conceptual soil models

320 into broad classifications ${ }^{94}$, and summarising the general processes (and ideally their associated 
321 equations) that need to be represented in models ${ }^{17}$. This methodology shows awareness of the

322 human and computational costs related to representing structural uncertainty in climate models,

323 which demands that only the most plausible sets of mechanisms are compared.

324 The second role for empiricists is to design and execute empirical studies that distinguish

325 which of the rapidly proliferating mechanisms put forth to govern soil $\mathrm{C}$ formation and

326 stabilisation $^{16,22,23,60}$, are most consistent with field observations of soil $\mathrm{C}$ turnover. The rapid

327 growth in development and application of fractionation and isotopic techniques that permit a

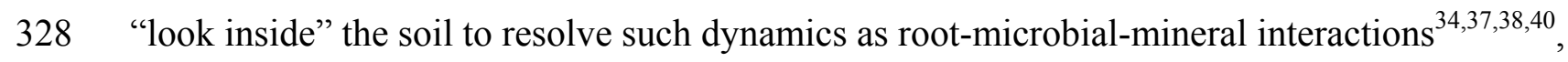

329 highlight the potential for such approaches to refine the sets of mechanisms that must be

330 represented in models. Empiricists can be guided in these efforts by the structural assumptions

331 about soil $\mathrm{C}$ turnover to which simulated soil $\mathrm{C}$ stock responses are most responsive. An

332 improved mechanistic understanding of soil $\mathrm{C}$ turnover can then go hand-in-hand with reductions

333 in model structural uncertainty and, consequently, increasing confidence in the magnitude of the

334 projected feedback (Fig. 4).

\section{Refine parameter estimates}

337 Once structural uncertainty is represented and reduced, the aim to lessen the spread in the 338 projected magnitude of the C-climate feedback by refining parameter estimates ${ }^{26,79,81}$ will be of

339 great value. The current ensemble of ESMs vary markedly in the assumed values of soil

340 parameters, such as the sensitivity of decay constants to warming ${ }^{27}$. Similarly, variation in even

341 the parameter value of a single physiological process in the microbial-explicit models, can mean

342 the difference between large versus no losses of soil C stocks under warming ${ }^{52}$. Notably, soil C

343 stocks are sensitive to a huge range of processes in these microbial models, including community 
344 composition, enzyme activities, carbon use efficiency, microbial turnover, and mineral surface

345 interactions ${ }^{19,48,65,95,96}$. Parameter values for these processes tend to be poorly constrained by

346 observations ${ }^{39,56,80,90,94}$. Hence, modellers can provide critical guidance to empiricists by

347 identifying processes where modelled soil C stocks are strongly sensitive to the assumed

348 parameter value. Such guidance will allow empiricists to focus on identifying the plausible range

349 of values observed in nature and how these values depend on environmental conditions ${ }^{57,97}$.

\section{Consider spatially-explicit processes}

352 A guiding principle in developing climate and Earth system models has been to represent major

353 processes, within a model, in a mathematically uniform manner across space. This principle has

354 been effective for representing physical atmospheric processes and also biological processes

355 such as photosynthesis, where trade-offs in the balance between leaf respiratory demands and

356 photosynthetic rates constrain the set of mechanisms and parameter values that can co-occur ${ }^{98}$.

357 However, soil $\mathrm{C}$ turnover is regulated by interacting physical and biological processes, with the

358 relative role of each process dependent on a complex suite of environmental conditions that vary

359 in space ${ }^{65,73}$. For example, the recent focus on the role of microbial-mineral surface interactions

360 in soil $\mathrm{C}$ stabilisation ${ }^{23}$, combined with a move away from ideas of inherent chemical

361 recalcitrance of plant inputs ${ }^{16,66,68}$, may fail to represent soil C turnover in organic soils where

362 mineral surfaces are not abundant ${ }^{22,99}$. Furthermore, there is evidence that mycorrhizal

363 associations are key arbiters of soil $\mathrm{C}$ stocks ${ }^{37,100}$, that plants can bypass microorganisms to

364 decompose soil $\mathrm{C}^{38}$, and that physico-chemical sorption/ desorption processes, and not biology,

365 may regulate soil $\mathrm{C}$ turnover ${ }^{1}$. Clearly there are a growing number of different and potentially

366 important controls on soil $\mathrm{C}$ stocks that remain poorly understood. As such, it is possible that no 
367 single structural representation of soil biogeochemistry will be effective at simulating soil C 368 turnover under warming across diverse landscapes.

369 The practical and computational costs of using different structural representations in

370 ESMs may be infeasible, but there needs to be an appreciation that even a single model structure

371 may need to represent dramatic shifts in the mechanisms underlying soil dynamics. As such, the

372 spatial and temporal scales at which models are parameterised and applied must be carefully

373 considered $^{94}$. For example, effective simulation of soil C turnover may require different

374 mechanisms to operate as the location changes from one underlain by a mineral to an organic

375 soil. These different mechanisms may even be required for the same location, where the turnover

376 of $\mathrm{C}$ in organic horizons and underlying mineral horizons are controlled by different factors ${ }^{99}$.

377 Initial investigations of such possibilities will be best facilitated by controlled experiments that

378 separately resolve $\mathrm{C}$ turnover in soil $\mathrm{C}$ fractions and horizons, and then test whether these

379 dynamics are better represented by models that use a common or spatially-dependent

380 mechanistic structure to simulate the total soil C stock.

\section{Establish long-term warming experiments}

383 Achieving real-world confidence in model projections may ultimately demand direct

384 observations of soil C stock responses to climate change ${ }^{26}$. Even once theoretical advances in 385 understanding soil C turnover are widely represented and refined in ESMs, there will likely

386 remain the expectation that projections should be compared to observations. Long-term field

387 ecosystem warming studies are therefore required that, given the expectation that dominant

388 controls on soil C turnover change with space ${ }^{16}$, are organised into networks that facilitate

389 adoption of standard approaches for robust comparison among studies ${ }^{41}$. Experimental field 
390 studies are not without limitations. Imposed step-changes in temperature may not elicit the same

391 responses as the observed chronic rise in temperatures. In addition, the few existing long-term

392 studies exemplify how even a detailed understanding of the processes governing the formation

393 and decomposition of different soil C fractions, may not permit accurate inferences about how

394 the soil C stock will respond in the longer term ${ }^{42}$. For example, organismal responses can lead to

395 surprises that modify direct effects of warming, meaning that anticipated losses of soil C stocks

396 may not necessarily occur ${ }^{30,42}$. Such long-term studies are arguably too few ${ }^{2}$ to benchmark model

397 projections against with any real confidence.

398 To be of most value for determining allowable $\mathrm{CO}_{2}$ emissions to meet specified climate

399 targets, field-warming experiments should be initiated now and/or existing warming experiments

400 extended to facilitate observations of soil C stock responses. These studies must be well

401 replicated, warm the aboveground as well as soils, and be of sufficiently long duration so that

402 changes in soil C stocks can be reliably assessed despite the 'noise' created by the slow turnover

403 of the total C stock and its pronounced fine-scale spatial variation in size (Fig. 1). Long durations

404 will also permit organismal responses to manifest at multiple temporal scales (Fig. 2), increasing

405 confidence that the observed responses might represent those of natural systems. Similarly, if

406 such long-term studies use isotopic and fractionation approaches ${ }^{36-39}$ to resolve the turnover of

407 soil C of differing sensitivities to warming, then inferences that shorter-term responses can be

408 used to estimate total $\mathrm{C}$ stock responses can be validated. If long-term studies are broadly

409 initiated, they may need to measure soil C stocks on a mass basis, and not simply C

410 concentrations and/or depth-dependent stocks given their inherent limitations ${ }^{43,44}$. These studies

411 will face the usual challenge of the limited duration of grants to fund research and so will 
412 demand a longer-term view of the value they offer in terms of improving confidence in the

413 effectiveness of greenhouse gas emission targets.

414

\section{Conclusions}

416 Major conceptual advances across the last 20 years in understanding soil $\mathrm{C}$ turnover are not yet

417 reflected in the way in which soil biogeochemistry is represented in ESMs. Evaluating these

418 advances in ESMs will identify how this new knowledge might alter expected responses of soil

419 C stocks to climate change. In turn, insights from the models will expedite gains in basic

420 understanding by identifying mechanisms that must be empirically researched before we can

421 accurately simulate soil $\mathrm{C}$ turnover. These activities may initially increase the spread in the

422 projected magnitude of soil C stock responses to warming, but should systematically improve

423 confidence in the projections by factoring conceptual uncertainties into recommendations to

424 manage human-induced changes in climate.

425

426 References

4271 Conant, R. T. et al. Temperature and soil organic matter decomposition rates - synthesis

428 of current knowledge and a way forward. Global Change Biol 17, 3392-3404 (2011).

4292 Lu, M. et al. Responses of ecosystem carbon cycle to experimental warming: a meta$430 \quad$ analysis. Ecology 94, 726-738 (2013).

4313 Dorrepaal, E. et al. Carbon respiration from subsurface peat accelerated by climate

432 warming in the subarctic. Nature 460, 616-619 (2013).

4334 Frey, S. D., Lee, J., Melillo, J. M. \& Six, J. The temperature response of soil microbial 434 efficiency and its feedback to climate. Nat Clim Change 3, 395-398 (2013). 
4355 Karhu, K. et al. Temperature sensitivity of soil respiration rates enhanced by microbial

$436 \quad$ community response. Nature $\mathbf{5 1 3}, 81-84$ (2014).

4376 Melillo, J. M. et al. Soil warming, carbon-nitrogen interactions, and forest carbon

$438 \quad$ budgets. P Natl Acad Sci USA 108, 9508-9512 (2011).

4397 Zhou, J. et al. Microbial mediation of carbon-cycle feedbacks to climate warming. Nat

$440 \quad$ Clim Change 2, 106-110 (2012).

4418 Friedlingstein, P. et al. Uncertainties in CMIP5 climate projections due to carbon cycle 442 feedbacks. J Climate 27, 511-526 (2014).

4439 Arora, V. K. et al. Carbon-concentration and carbon-climate feedbacks in CMIP5 Earth $444 \quad$ System Models. J Climate 26, 5289-5314 (2013).

44510 Jones, C. et al. Twenty-first-century compatible $\mathrm{CO}_{2}$ emissions and airborne fraction 446 simulated by CMIP5 Earth system models under four representative concentration 447 pathways. J Climate 26, 4398-4413 (2013). This study laid out the idea of 'allowable 448 emissions', highlighting the importance of terrestrial carbon cycle uncertainty in 449 projecting allowable greenhouse gas emissions that are compatible with specified $450 \quad$ climate targets.

45111 Ciais, P. et al. in Climate Change 2013: The Physical Science Basis. Contribution of 452 Working Group I to the Fifth Assessment Report of the Intergovernmental Panel on 453 Climate Change (eds Stocker, T.F. et al.) 465-570 (Cambridge Univ. Press, 2013).

45412 Jobbágy, E. G. \& Jackson, R. B. The vertical distribution of soil organic carbon and its 455 relation to climate and vegetation. Ecol App 10, 423-436 (2000).

45613 Tarnocai, C. et al. Soil organic carbon pools in the northern circumpolar permafrost 457 region. Global Biogeochem Cy 23, GB2023 (2009). 
45814 Denman, K. L. et al. in Climate Change 2007: The Physical Science Basis. Contribution

459 of Working Group I to the Fourth Assessment Report of the Intergovernmental Panel on

460 Climate Change (eds Solomon, S. et al.) 499-587 (Cambridge Univ. Press, 2007).

46115 Giardina, C. P., Litton, C. M., Crow, S. E. \& Asner, G. P. Warming-related increases in 462 soil $\mathrm{CO}_{2}$ efflux are explained by increased below-ground carbon flux. Nat Clim Change

$4634,822-827$ (2014). This study across an elevational gradient in a tropical forest,

464 showed that the positive relationship between temperature and soil respiration rates

465 occurred not through expected direct warming effects on soil C decomposition but

466 because of higher plant $\mathrm{C}$ inputs belowground.

46716 Schmidt, M. W. I. et al. Persistence of soil organic matter as an ecosystem property.

$468 \quad$ Nature 478, 49-56 (2011).

46917 Davidson, D. A., Savage, K. E. \& Finzi, A. C. A big-microsite framework for soil carbon 470 modeling. Global Change Biol 20, 3610-3620 (2014). This opinion piece proposed a

471 modular model structure to represent the complexity of processes influencing soil C

472 turnover, bringing representations of soil C turnover in line with those of

473 photosynthesis in ecosystem and global models.

47418 Wieder, W. R., Grandy, A. S., Kallenbach, C. M. \& Bonan, G. B. Integrating microbial

475 physiology and physio-chemical principles in soils with the MIcrobial-MIneral Carbon

$476 \quad$ Stabilization (MIMICS) model. Biogeosciences 11, 1147-1185 (2014).

47719 Wieder, W. R., Bonan, G. B. \& Allison, S. D. Global soil carbon projections are

478 improved by modelling microbial processes. Nat Clim Change 3, 909-912 (2013).

47920 Jenkinson, D. S., Adams, D. E. \& Wild, A. Model estimates of $\mathrm{CO}_{2}$ emissions from soil $480 \quad$ in response to global warming. Nature 351, 304-306 (1991). 
48121 Todd-Brown, K. E. O., Hopkins, F. M., Kivlin, S. N., Talbot, J. M. \& Allison, S. D. A

482 framework for representing microbial decomposition in coupled climate models.

483 Biogeochemistry 109, 19-33 (2012).

48422 Castellano, M. J., Mueller, K. E., Olk, D. C., Sawyer, J. E. \& Six, J. Integrating plant 485 litter quality, soil organic matter stabilization, and the carbon saturation concept. Global

486 Change Biol 21, 3200-3209 (2015). This opinion laid out a new conceptual model that

487 integrates advances in understanding of how microbial physiology controls soil C

488 cycling, with established physico-chemical principles that dictate whether

$489 \quad$ physiological responses influence soil C stocks.

49023 Cotrufo, M. F., Wallenstein, M. D., Boot, C. M., Denef, K. \& Paul, E. The Microbial

491 Efficiency-Matrix Stabilization (MEMS) framework integrates plant litter decomposition

492 with soil organic matter stabilization: do labile plant inputs form stable soil organic

493 matter? Global Change Biol 19, 988-995 (2013).

49424 Friedlingstein, P. et al. Climate-carbon cycle feedback analysis: Results from the C ${ }^{4}$ MIP

495 model intercomparison. J Climate 19, 3337-3353 (2006).

49625 Cox, P. M. et al. Sensitivity of tropical carbon to climate change constrained by carbon

497 dioxide variability. Nature 494, 341-344 (2013).

49826 Exbrayat, J.-F., Pitman, A. J. \& Abramowitz, G. Response of microbial decomposition to 499 spin-up explains CMIP5 soil carbon range until 2100. Geosci Model Dev 7, 3481-3504

$500 \quad$ (2014).

50127 Todd-Brown, K. E. O. et al. Causes of variation in soil carbon simulations from CMIP5

502 Earth system models and comparison with observations. Biogeosciences 10, 1717-1736

503 (2013). 
50428 Hawkins, E. \& Sutton, R. The potential to narrow uncertainty in regional climate

505 predictions. Bull Amer Meteor Soc 90, 1095-1107 (2009). This study identified sources

506 of uncertainty in physical climate projections, revealing that at decadal timescales

507 model uncertainty is a dominant uncertainty source at regional and global scales,

508 highlighting the large gains in certainty possible by refining climate models.

50929 Knutti, R. \& Sedláček, J. Robustness and uncertainties in the new CMIP5 climate model

510 projections. Nat Clim Change 3, 369-373 (2013). This study showed that model spread

511 (i.e. uncertainty) in physical-based climate projections changed little from the fourth

512 to fifth assessment report of the IPCC, yet the authors argued that confidence in

513 these projections should be substantially greater given major advances in

514 representing mechanistic understanding.

$51530 \quad$ Melillo, J. M. et al. Soil warming and carbon-cycle feedbacks to the climate system.

$516 \quad$ Science 298, 2173-2176 (2002).

$51731 \quad$ Kirschbaum, M. U. F. The temperature dependence of organic-matter decomposition-

$518 \quad$ still a topic of debate. Soil Biol Biochem 38, 2510-2518 (2006).

51932 Torn, M. S., Vitousek, P. M. \& Trumbore, S. E. The influence of nutrient availability on 520 soil organic matter turnover estimated by incubations and radiocarbon modeling.

$521 \quad$ Ecosystems 8, 352-372 (2005).

52233 Lehmann, J. et al. Spatial complexity of soil organic matter forms at nanometre scales.

$523 \quad$ Nat Geosci 1, 238-242 (2008).

$52434 \quad$ Vogel, C. et al. Submicron structures provide preferential spots for carbon and nitrogen

525 sequestration in soils. Nat Comm 5, 2947 (2014). This empirical study showed that

526 decomposition of plant $\mathrm{C}$ inputs into more stable soil $\mathrm{C}$ fractions occurred 
preferentially via association with mineral surfaces already clustered with organic matter, changing ideas about how soil clay content relates to the potential of soils to sequester $C$.

53035 Strickland, M. S., DeVore, J. L., Maerz, J. C. \& Bradford, M. A. Grass invasion of a 531 hardwood forest is associated with declines in belowground carbon pools. Global Change $532 \quad$ Biol 16, 1338-1350 (2010).

53336 Bradford, M. A., Keiser, A. D., Davies, C. A., Mersmann, C. A. \& Strickland, M. S. 534 Empirical evidence that soil carbon formation from plant inputs is positively related to 535 microbial growth. Biogeochemistry 113, 271-281 (2013).

53637 Clemmensen, K. E. et al. Roots and associated fungi drive long-term carbon 537 sequestration in boreal forest. Science 339, 1615-1618 (2013).

53838 Keiluweit, M. et al. Mineral protection of soil carbon counteracted by root exudates. Nat 539 Clim Change 5, 588-595 (2015). This empirical study showed that plant-root inputs 540 could directly liberate soil $\mathrm{C}$ from protective associations with minerals, bypassing the presumed direct microbial role in decomposing this 'stable' soil C fraction.

54239 Liang, C. \& Balser, T. C. Warming and nitrogen deposition lessen microbial residue 543 contribution to soil carbon pool. Nat Comm 3, 1222 (2012).

$544 \quad 40 \quad$ Neff, J. C. et al. Variable effects of nitrogen additions on the stability and turnover of soil $545 \quad$ carbon. Nature 419, 915-917 (2002).

54641 Torn, M. S. et al. A call for international soil experiment networks for studying, 547 predicting, and managing global change impacts. SOIL 1, 575-582 (2015).

54842 Sistla, S. A. et al. Long-term warming restructures Arctic tundra without changing net 549 soil carbon storage. Nature 497, 615-618 (2013). 
55043 Gifford, R. M. \& Roderick, M. L. Soil carbon stocks and bulk density: spatial or

$551 \quad$ cumulative mass coordinates as a basis of expression? Global Change Biol 9, 1507-1514 (2003). This study showed how conventional soil sampling procedures might fail to measure real changes in soil C stocks with time, and the authors proposed that a mass-dependent method be broadly adopted to address these issues.

55544 Hopkins, D. W. et al. Soil organic carbon contents in long-term experimental grassland plots in the UK (Palace Leas and Park Grass) have not changed consistently in recent decades. Global Change Biol 15, 1739-1754 (2009).

$55845 \quad$ Schmitz, O. J. et al. Animating the carbon cycle. Ecosystems 17, 344-359 (2014).

55946 Reich, P. B. The carbon dioxide exchange. Science 329, 774-775 (2010).

56047 Bradford, M. A. et al. Thermal adaptation of soil microbial respiration to elevated temperature. Ecol Lett 11, 1316-1327 (2008).

56248 Hagerty, S. B. et al. Accelerated microbial turnover but constant growth efficiency with $563 \quad$ warming in soil. Nat Clim Change 4, 903-906 (2014).

56449 Crowther, T. W. \& Bradford, M. A. Thermal acclimation in widespread heterotrophic soil $565 \quad$ microbes. Ecol Lett 16, 469-477 (2013).

56650 Crowther, T. W. et al. Biotic interactions mediate soil microbial feedbacks to climate $567 \quad$ change. P Natl Acad Sci USA 112, 7033-7038 (2015).

$56851 \quad$ Mahecha, M. D. et al. Global convergence in the temperature sensitivity of respiration at 569 ecosystem level. Science 329, 838-840 (2010).

57052 Allison, S. D., Wallenstein, M. D. \& Bradford, M. A. Soil-carbon response to warming 571 dependent on microbial physiology. Nat Geosci 3, 336-340 (2010). 
57253 Allison, S. D. Modeling adaptation of carbon use efficiency in microbial communities.

$573 \quad$ Front Microbiol 5, e571 (2014).

57454 Todd-Brown, K. E. O. et al. Changes in soil organic carbon storage predicted by Earth 575 system models during the 21st century. Biogeosciences 11, 2341-2356 (2014).

57655 Davidson, E. A. \& Janssens, I. A. Temperature sensitivity of soil carbon decomposition 577 and feedbacks to climate change. Nature 440, 165-173 (2006).

57856 Carvalhais, N. et al. Global covariation of carbon turnover times with climate in 579 terrestrial ecosystems. Nature 514, 213-217 (2014).

58057 Davidson, E. A., Samanta, S., Caramori, S. S. \& Savage, K. The Dual Arrhenius and 581 Michaelis-Menten kinetics model for decomposition of soil organic matter at hourly to 582 seasonal time scales. Global Change Biol 18, 371-384 (2012).

58358 Schuur, E. A. G. et al. Climate change and the permafrost carbon feedback. Nature 520, $584 \quad 171-179(2015)$.

58559 Bradford, M. A. Thermal adaptation of decomposer communities in warming soils. Front $586 \quad$ Microbiol 4, e333 (2013).

58760 Lehmann, J. \& Kleber, M. The contentious nature of soil organic matter. Nature 528, 60$588 \quad 68(2015)$

58961 Miltner, A., Bombach, P., Schmidt-Brücken, B. \& Kästner, M. SOM genesis: microbial 590 biomass as a significant source. Biogeochemistry 111, 41-55 (2012).

59162 Liang, C. \& Balser, T. C. Microbial production of recalcitrant organic matter in global 592 soils: implications for productivity and climate policy. Nat Rev Microbiol 9, 75-77 $593 \quad$ (2010). 
59463 Ahrens, B., Braakhekke, M. C., Guggenberger, G., Schrumpf, M. \& Reichstein, M.

595 Contribution of sorption, DOC transport and microbial interactions to the ${ }^{14} \mathrm{C}$ age of a 596 soil organic carbon profile: Insights from a calibrated process model. Soil Biol Biochem $597 \quad \mathbf{8 8}, 390-402(2015)$.

59864 Grandy, A. S. \& Neff, J. C. Molecular C dynamics downstream: The biochemical 599 decomposition sequence and its impact on soil organic matter structure and function. Sci Total Environ 404, 297-307 (2008).

60165 Tang, J. \& Riley, W. J. Weaker soil carbon-climate feedbacks resulting from microbial 602 and abiotic interactions. Nat Clim Change 5, 56-60 (2015). This study showed that use of a dynamic, as opposed to the conventional static, model structure to represent spatiotemporal dependencies in temperature, microbial and mineral surface turnover is governed by accessibility not recalcitrance. Global Change Biol 18, 1781-

60967 Doetterl, S. et al. Soil carbon storage controlled by interactions between geochemistry $610 \quad$ and climate. Nature Geosci 8, 780-783 (2015).

61168 Marschner, B. et al. How relevant is recalcitrance for the stabilization of organic matter 612 in soils? J Plant Nutr Soil Sc 171, 91-110 (2008).

61369 Crowther, T. W. et al. Environmental stress response limits microbial necromass 614 contributions to soil organic carbon. Soil Biol Biochem 85, 153-161 (2015).

61570 Högberg, P. \& Read, D. J. Towards a more plant physiological perspective on soil 616 ecology. Trends Ecol Evol 21, 548-554 (2006). 
61771 van Hees, P. A. W., Jones, D. L., Finlay, R., Godbold, D. L. \& Lundström, U. S. The

618 carbon we do not see-the impact of low molecular weight compounds on carbon

619 dynamics and respiration in forest soils: a review. Soil Biol Biochem 37, 1-13 (2005).

62072 Pittelkow, C. M. et al. Productivity limits and potentials of the principles of conservation

$621 \quad$ agriculture. Nature 517, 365-368 (2015).

62273 Koven, C. D., Lawrence, D. M. \& Riley, W. J. Permafrost carbon-climate feedback is

623 sensitive to deep soil carbon decomposability but not deep soil nitrogen dynamics. P Natl

$624 \quad$ Acad Sci USA 112, 3752-3757 (2015).

62574 Collins, M. et al. in Climate Change 2013: The Physical Science Basis. Contribution of

626 Working Group I to the Fifth Assessment Report of the Intergovernmental Panel on

627 Climate Change (eds Stocker, T.F. et al.) 1029-1136 (Cambridge Univ. Press, 2013).

62875 Sierra, C. A., Müller, M. \& Trumbore, S. E. Models of soil organic matter

629 decomposition: the SoilR package, version 1.0. Geosci Model Dev Discuss 5, 1045-1060

$630 \quad$ (2012).

63176 Xia, J., Luo, Y., Wang, Y.-P. \& Hararuk, O. Traceable components of terrestrial carbon

632 storage capacity in biogeochemical models. Global Change Biol 19, 2104-2116 (2013).

$63377 \quad$ Flato, G. et al. in Climate Change 2013: The Physical Science Basis. Contribution of

634 Working Group I to the Fifth Assessment Report of the Intergovernmental Panel on

635 Climate Change (eds Stocker, T.F. et al.) 741-866 (Cambridge Univ. Press, 2013).

63678 Stocker, T. F. et al. in Climate Change 2013: The Physical Science Basis. Contribution of

637 Working Group I to the Fifth Assessment Report of the Intergovernmental Panel on

638 Climate Change (eds Stocker, T.F. et al.) 33-115 (Cambridge Univ. Press, 2013). 
63979 Wenzel, S., Cox, P. M., Eyring, V. \& Friedlingstein, P. Emergent constraints on climate640 carbon cycle feedbacks in the CMIP5 Earth system models. J Geophys Res 119, 794-807 (2014).

64280 Luo, Y. et al. Towards more realistic projections of soil carbon dynamics by Earth 643 System Models. Global Biogeochem Cy 29, doi:10.1002/2015GB005239 (2015).

64481 Luo, Y., Keenan, T. F. \& Smith, M. Predictability of the terrestrial carbon cycle. Global $645 \quad$ Change Biol 21, 1737-1751 (2015).

64682 Reich, P. B. et al. Nitrogen limitation constrains sustainability of ecosystem response to $647 \quad \mathrm{CO}_{2}$. Nature 440, 922-925 (2006).

64883 Wieder, W. R., Cleveland, C. C., Smith, W. K. \& Todd-Brown, K. Future productivity 649 and carbon storage limited by terrestrial nutrient availability. Nat Geosci 8, 441-444 $650 \quad$ (2015).

65184 Zhang, Q., Wang, Y. P., Matear, R. J., Pitman, A. J. \& Dai, Y. J. Nitrogen and 652 phosphorous limitations significantly reduce future allowable $\mathrm{CO}_{2}$ emissions. Geophys $653 \quad$ Res Lett 41, 632-637 (2014).

65485 Hararuk, O., Smith, M. J. \& Luo, Y. Microbial models with data-driven parameters 655 predict stronger soil carbon responses to climate change. Global Change Biol 21, 2439$6562453(2015)$.

65786 Sulman, B. N., Phillips, R. P., Oishi, A. C., Shevliakova, E. \& Pacala, S. W. Microbe658 driven turnover offsets mineral-mediated storage of soil carbon under elevated $\mathrm{CO}_{2}$. Nat $659 \quad$ Clim Change 4, 1099-1102 (2014). 
87 Wieder, W. R., Grandy, A. S., Kallenbach, C. M., Taylor, P. G. \& Bonan, G. B.

Representing life in the Earth system with soil microbial functional traits in the MIMICS model. Geosci Model Dev Discuss 8, 2011-2052 (2015).

88 Parton, W. J., Schimel, D. S., Cole, C. V. \& Ojima, D. S. Analysis of factors controlling soil organic matter levels in Great Plains grasslands. Soil Sci Soc Am J 51, 1173-1179 (1987).

89 Bonan, G. B., Hartman, M. D., Parton, W. J. \& Wieder, W. R. Evaluating litter decomposition in earth system models with long-term litterbag experiments: an example using the Community Land Model version 4 (CLM4). Global Change Biol 19, 957-974 (2013).

Sinsabaugh, R. L., Manzoni, S., Moorhead, D. L. \& Richter, A. Carbon use efficiency of microbial communities: stoichiometry, methodology and modelling. Ecol Lett 16, 930939 (2013). degradation pathways. Global Change Biol 22, 121-136 (2016). mixed tundra and a fen within a hydrologically diverse Arctic landscape: 1. Modeling versus measurements. JGR-Biogeosciences 120, 1366-1387 (2015). contrasting models for the turnover of organic carbon in soil. Global Change Biol 11,

68194 Manzoni, S. \& Porporato, A. Soil carbon and nitrogen mineralization: Theory and models across scales. Soil Biol Biochem 41, 1355-1379 (2009). 
68395 German, D. P., Marcelo, K. R. B., Stone, M. M. \& Allison, S. D. The Michaelis-Menten

684 kinetics of soil extracellular enzymes in response to temperature: a cross-latitudinal

685 study. Global Change Biol 18, 1468-1479 (2012).

68696 Tucker, C. L., Bell, J., Pendall, E. \& Ogle, K. Does declining carbon-use efficiency

687 explain thermal acclimation of soil respiration with warming? Global Change Biol 19, $688 \quad 252-263(2013)$.

68997 Suseela, V., Conant, R. T., Wallenstein, M. D. \& Dukes, J. S. Effects of soil moisture on 690 the temperature sensitivity of heterotrophic respiration vary seasonally in an old-field 691 climate change experiment. Global Change Biol 18, 336-348 (2012).

69298 Shipley, B., Lechowicz, M. J., Wright, I. \& Reich, P. B. Fundamental trade-offs 693 generating the worldwide leaf economics spectrum. Ecology 87, 535-541 (2006).

69499 Manning, P. et al. Simple measures of climate, soil properties and plant traits predict 695 national-scale grassland soil carbon stocks. J Appl Ecol 52, 1188-1196 (2015).

696100 Averill, C., Turner, B. L. \& Finzi, A. C. Plant-decomposer competition for nitrogen 697 increases soil carbon storage in ecto- and ericoid-mycorrhizal ecosystems. Nature 505, $698 \quad 543-545(2014)$.

699

700 Correspondence and requests for materials should be addressed to Mark A. Bradford.

701

702 Acknowledgements The work was supported by grants from the U.S. National Science

703 Foundation (DEB-1021098 and DEB-1457614) and The Royal Netherlands Academy of Arts

704 and Sciences (Visiting Professors Programme) to M.A.B. The Yale Climate and Energy Institute, 705 and a Marie Skłodowska Curie Fellowship, supported T.W.C. W.R.W. was supported by grants 
706 from the U.S. Department of Agriculture (NIFA 2015-67003-23485) and U.S. Department of

707 Energy (TES DE-SC0014374). Thanks to Wim van der Putten and Fiona Cotter for comments

708 on an earlier draft of this script.

709

710 Author Contributions M.A.B. conceived the overall idea for this manuscript and together with

711 T.W.C. synthesised empirical and with W.R.W. modelling knowledge. M.A.B., W.R.W., G.B.B.,

712 N.F., P.A.W. and T.W.C. then co-developed the ideas and written material.

713

714 Author Information Reprints and permissions information is available at

715 www.nature.com/reprints. The authors declare no competing financial interests. Readers are

716 welcome to comment on the online version of the paper.

718 Figure 1 Soil $\mathrm{C}$ stocks are the net result of outputs and inputs of plant $\mathrm{C}$ but most warming

719 research focuses only on outputs, making stock responses highly uncertain. Warming-

720 induced outputs (red arrows) in the schematic are represented as $\mathrm{CO}_{2}$ fluxes, reflecting the

721 assumption in ESMs that the land C-climate feedback occurs through warming stimulating the

722 activities of soil microorganisms that decompose soil C. Losses of soil $\mathrm{C}$ do occur through other

723 pathways (lateral transport and soil erosion), but warming effects on these losses are not well

724 characterised. Instead, the majority of warming studies focus on decomposition of soil $\mathrm{C}$ to $\mathrm{CO}_{2}$.

725 Despite strong warming effects on decomposition, there are very few observed reductions in soil

726 C stocks. This paucity of data reflects the fact that there has been far less research (depicted by

727 thickness of flux arrow lines) into how warming affects soil $\mathrm{C}$ formation through plant inputs

728 (green down arrows) versus its effects on decomposition. It also reflects the signal-to-noise 
729 issues in detecting a change in soil C stocks, given marked local variation (horizontally as well

730 as with depth) in soil C stocks and the fact only a proportion of this $\mathrm{C}$ is likely sensitive to

731 warming-induced losses.

733 Figure 2 Timescale of organismal responses to warming, with the potential that initial

734 increases in microbial activity are exacerbated or mitigated through physiological,

735 population and community level responses as the warming perturbation continues.

736 Modelled land C-climate feedbacks rely on warming-mediated increases in the potential

737 activities of microbial enzymes, which catalyse the decomposition of soil C, being maintained in

738 the longer term. Yet, physiological acclimation and turnover in populations and communities -

739 both aboveground and belowground (represented as plants and soil microbes, respectively) -

740 may modify the assumed translation of this initial cell-level warming response directly to

741 changes in soil C stocks. How the responses at intermediate levels of biological organisation

742 modify this translation becomes increasingly uncertain with time, given the large and diverse

743 array of interactions that can occur to re-structure communities.

745 Figure 3 The dual role of soil microbes as the agents of both soil $\mathrm{C}$ decomposition and

746 stabilisation. A new conceptualisation of how soil $\mathrm{C}$ is formed and stabilised emphasises that

747 plant-C inputs on which microbes grow most efficiently result in larger protected stocks of soil

748 C. Warming-induced increases in decomposition rates may then cause more unprotected (i.e.

749 more warming sensitive) soil $\mathrm{C}$ to be converted into stable pools, ultimately mitigating the

750 presumed land C-climate feedback because accelerated decomposition rates are balanced by

751 elevated formation rates. The grey-hatched arrow depicts this theoretical shunt of soil C from 
752 more to less temperature-sensitive pools under warming via the microbial funnel into microbial 753 product-mineral complexes.

755 Figure 4 Proposed activities to address low confidence in the projected magnitude of

756 carbon-climate feedbacks. Shown is a timeline for major initiatives (see text) that empiricists

757 and modellers can act on to address the low confidence and wide projected spread in soil C stock

758 responses to warming. Real-world confidence (inverted triangle) in the projected magnitude of

759 these responses increases when different assumptions (i.e. structural uncertainty) about the

760 mechanisms governing soil $\mathrm{C}$ turnover are represented in models, which then guides empirical

761 research to advance understanding of the mechanisms to which the models are most sensitive.

762 The trajectory of change in the spread among models of the projected magnitude of the feedback

763 is less assured and may increase when structural uncertainty is represented. To establish

764 allowable emissions of greenhouse gases to meet specified climate targets, high confidence in

765 widely divergent projections is superior to low confidence in a narrow range of projections,

766 because policy can then be developed in light of the knowledge that the best available science is

767 considered. 
Certainty in temperature response of plants and microbes

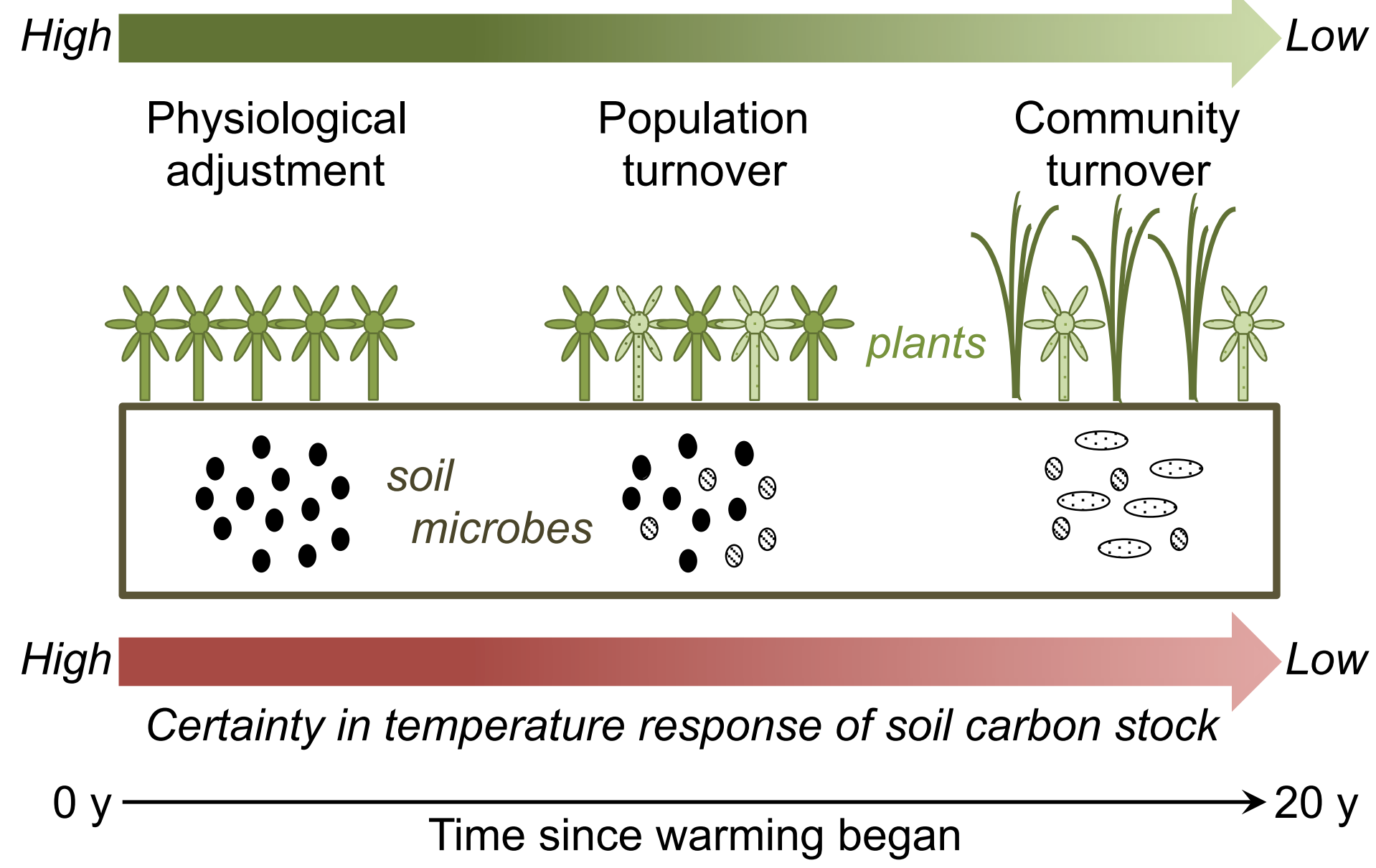




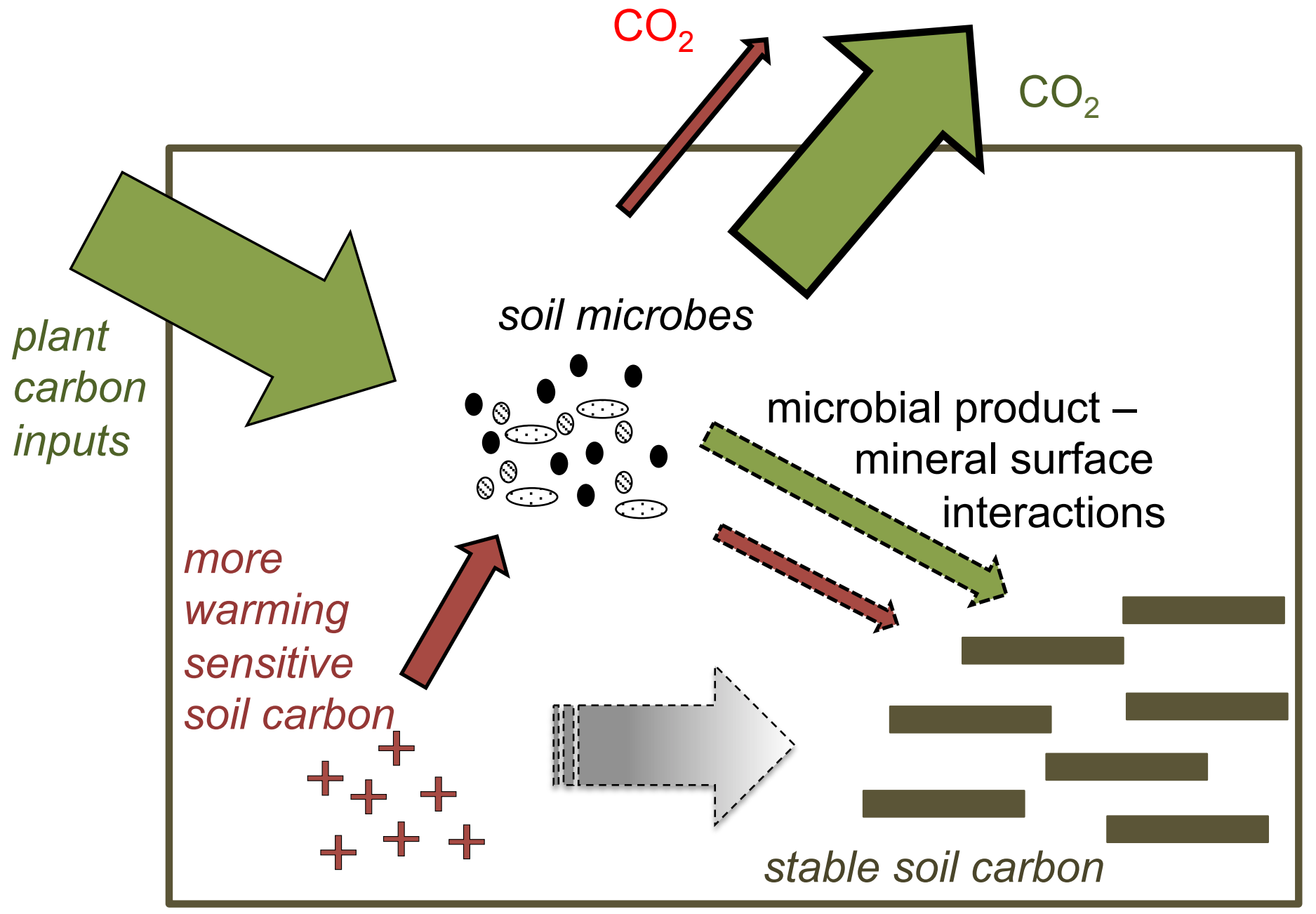




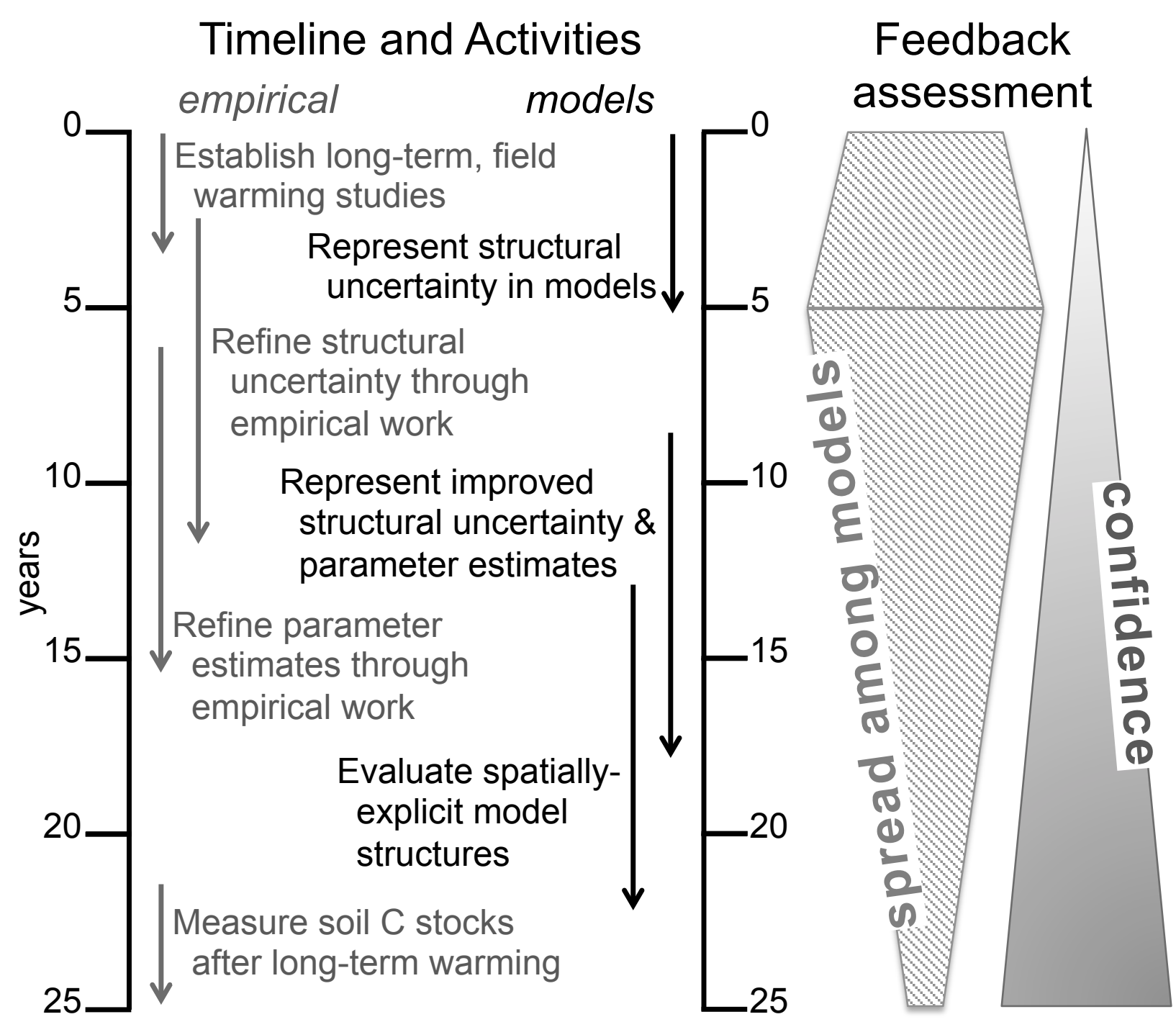

